\title{
Some Insights into Mechanisms Involved in Continuous Casting
}

\author{
K. C. Mills, ${ }^{1, *}$ P. E. Ramirez-Lopez ${ }^{2}$ and P. D. Lee $^{3}$ \\ ${ }^{1}$ Department of Materials, Imperial College, London, UK \\ ${ }^{2}$ Casting and Flow Simulation Group, Swerea MEFOS, \\ Luleå, Sweden \\ ${ }^{3}$ Manchester X-Ray Imaging Facility, School of Materials, \\ The University of Manchester, Manchester, UK
}

\begin{abstract}
A mathematical model of the continuous casting process for steel has been developed. This coupled model predicts metal flow, slag infiltration, shell solidification and heat flux. The model predicts values for the thicknesses of the solid and liquid slag films and the solidified shell, powder consumption and heat fluxes, all of which are in excellent agreement with plant data. The model has been used to study the mechanisms involved in (i) slag entrapment, (ii) the effect of mould oscillation on powder consumption, heat flux and shell solidification, (iii) oscillation mark (OM) formation and (iv) high and low frequency fluctuations.
\end{abstract}

Keywords. Continuous casting, slag-infiltration, heat flux, slag-entrapment, oscillation marks.

$\operatorname{PACS}^{\circledR}(2010) .47 .11 .-j, 44.05 .+e$, 64.70.D-.

\section{Introduction}

The continuous casting of steel is a highly-successful process; more than 1 billion tonnes are cast per year by this method. Steel from the ladle is poured into a tundish and then flows through a submerged entry nozzle (SEN) into a water-cooled, copper mould (Figure 1(a)). The molten steel solidifies to form a shell. The sticking of the shell to the mould is prevented by (i) adding a mould flux and (ii) by oscillating the mould. Mould flux is added to the top of the mould where it sinters (and forms a bed) and then melts to form a molten slag pool. Molten slag infiltrates into the mould/shell gap and forms a slag layer consisting of a liquid slag film (ca. $0.1 \mathrm{~mm}$ thick) and a solid slag layer (ca. $2 \mathrm{~mm}$ thick) as shown in Figure 1(b). The thicknesses of the liquid $\left(d_{\text {liquid }}\right)$ and solid slag layer $\left(d_{\text {solid }}\right)$ determine, respectively, the level of lubrication supplied to the shell and the magnitude of the horizontal heat flux between shell and mould [1].

\footnotetext{
* Corresponding author: K. C. Mills, Department of Materials, Imperial College, London SW7 2AZ, UK; E-mail: k.mills@imperial.ac.uk.
}

Received: February 9, 2012. Accepted: February 18, 2012.
Continuous casting is a complex process involving a large number of parameters (e.g. metal flow, heat transfer, oscillation characteristics, thermo-mechanical properties of the steel, etc...). These parameters are strongly inter-dependent. For instance, if the casting speed is increased to increase productivity, this will affect (i) the slag infiltration (i.e. lubrication), (ii) the heat transfer between shell and mould, and (iii) increase turbulence in the metal flow. Each of these can, in turn, have a collateral effect on the process. Despite this, most process control and quality issues can usually be solved by focusing on the particular defect. For instance, longitudinal cracking can be dealt with by reducing the horizontal heat flux. However, with any remedial action there is always the possibility that the action taken will affect other parameters and trigger other problems. Consequently, there is an urgent need for a reliable mathematical model of the processes occurring in the continuous casting mould which can accurately predict the effects of changing parameters like casting speed, slag properties, steel grade, etc....

Most models, to date, have been based on numerical fitting of plant data (e.g. mould temperatures obtained with instrumented moulds) which provide reasonable predictions when the operating conditions are similar to those for the data acquisition but are unreliable when applied to conditions far from those of the original data.

The objective of this work was to develop a 2dimensional (2D) model which couples metal flow, slag flow (infiltration) with heat transfer and steel solidification and to use this model to gain insights into the mechanisms occurring in the mould (e.g. slag infiltration, slag entrapment and the formation of oscillation marks).

\section{Model Development}

The model used in this study couples a flow model with a heat transfer and solidification model. Details of the model development and implementation have been published elsewhere [2], this paper will focus on its application, after a brief overview of the key assumptions and equations solved.

The flow model was based on FLUENT and solves the Navier-Stokes equations for the metal-slag flow and calculates the interface between slag and metal using the Volume of Fluid (VOF) approach [3] based on the Continuum Surface Force (CSF) method [5]. The $\kappa-\varepsilon$ turbulence model [4] is used to account for the turbulence in the system. The heat flux model solves the Fourier equations whilst the heat extracted by the water-cooling jacket is calculated using a heat 


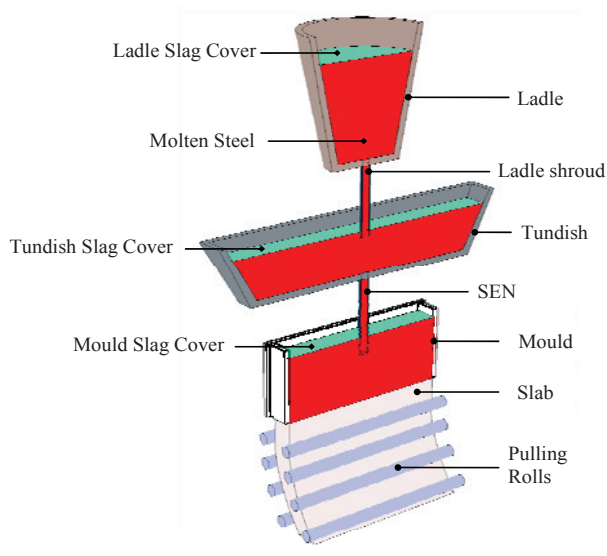

(a)

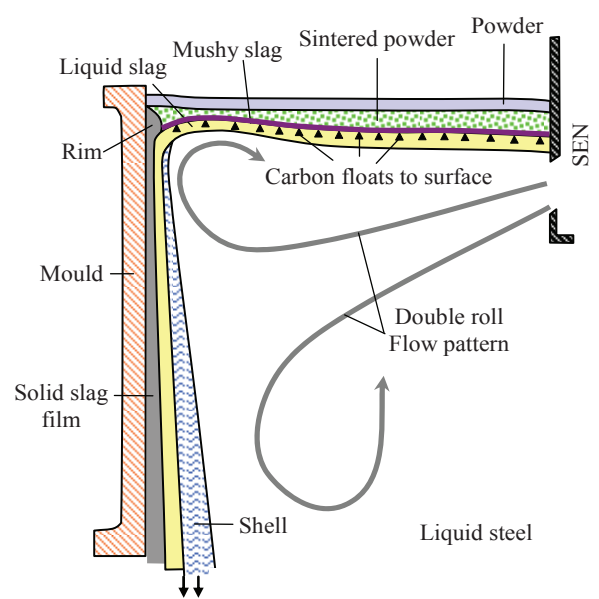

(b)

Figure 1. Schematic diagram showing (a) continuous casting process and (b) various phases formed in the mould.

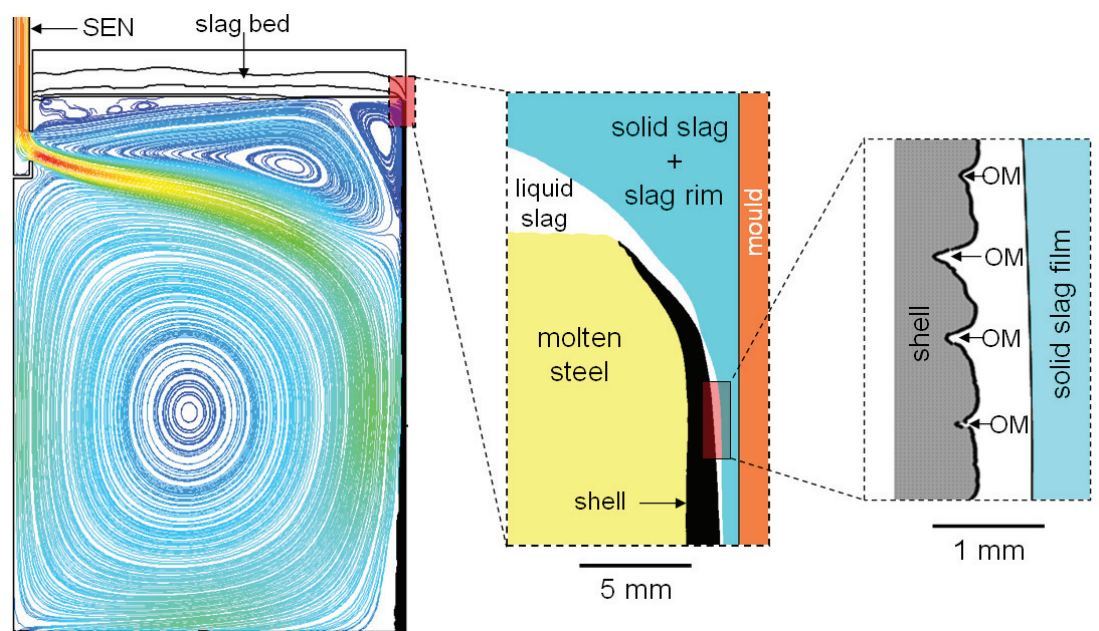

Figure 2. Model predictions showing flows, shell, solid and liquid slag films, standing waves and formation of oscillation marks (OM's).

transfer coefficient related to the Nusselt number. The principal resistances to horizontal heat flow are (i) the thickness of the slag film divided by its thermal conductivity, $k$ i.e. $\left(d_{\text {film }} / k_{\text {film }}\right)=(d / k)_{\text {liquid }}+(d / k)_{\text {solid }}$ and (ii) the interfacial resistance $\left(R_{\text {int }}\right)$ at the $\mathrm{Cu} / \mathrm{slag}$ interface (specified).

The model is $2 \mathrm{D}$ and assumes symmetry; hence the domain is half the caster width, including the SEN, mould (1.88 $\mathrm{m}$ width) and water cooling channels. In height the domain goes from the air above the caster to $1 \mathrm{~m}$ of slab after the mould exit. The solid shell surface was defined using the phase fraction map and the interface between solid and liquid slag films was defined by the break temperature $\left(T_{\mathrm{br}}\right)$ of the mould flux. The following procedure was adopted (i) the metal flow was allowed to develop for at least $1000 \mathrm{~s}$, (ii) then a $50 \mathrm{~mm}$ patch (representing the bed) was added and (iii) a steady flow was allowed to develop for at least another $2000 \mathrm{~s}$ to establish fully-developed flow, heat transfer and slag infiltration conditions $[1,6]$. Input data consisted of materials properties for slag and metal $\left(T_{\mathrm{br}}, T_{\text {solidus }}\right.$, density, viscosity, thermal conductivity, interfacial tension and $R_{\text {int }}$ ) and casting parameters (casting speed, frequency, stroke, superheat) $[1,6]$. It should be noted that the model makes no assumptions concerning (i) solid and liquid slag film thicknesses and (ii) the shape of the steel meniscus. These are both results from the calculations.

\section{Results and Discussion}

A sensitivity study was carried out $[2,6]$ in which the effects of varying parameters (e.g. casting speed, slag viscosity, stroke, oscillation frequency, interfacial resistance and break temperature on powder consumption, heat flux, shell and slag film thickness were determined.

A reference point located $45 \mathrm{~mm}$ below the meniscus on the narrow face was used for the measurements of heat flux, powder consumption, etc. This site was selected to coincide with the location of the maximum heat flux which also co- 


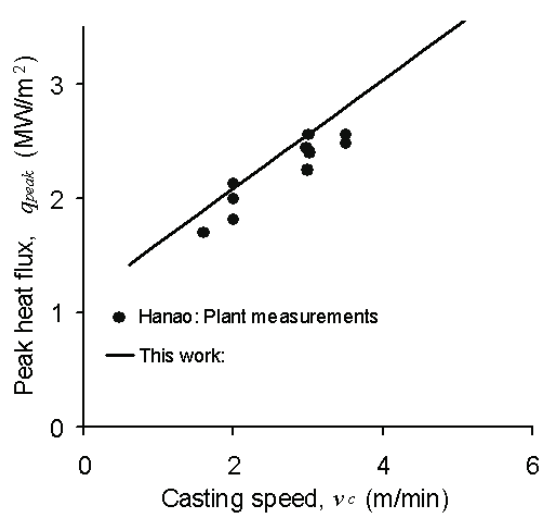

(a)

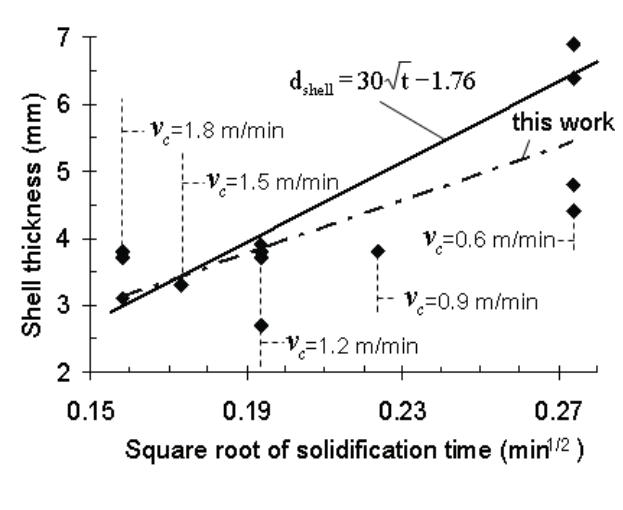

(b)

Figure 3. Comparison of Hanao et al. plant measurements [7, 8] with model predictions for (a) heat flux as a function of casting speed and (b) shell thickness as function of (solidification time $)^{0.5} ; \diamond$, dash-dot line $=$ predictions; solid line $=$ measurements.

incides with the location used by Hanao et al. [7] for their on-plant heat flux measurements.

\subsection{Comparison of Model Predictions with Plant Data}

It can be seen from Figure 2 that the model correctly predicts:

(i) The formation of a slag rim.

(ii) The formation of liquid and solid slag layers with thicknesses of $0.12-0.6 \mathrm{~mm}$ and $1-3 \mathrm{~mm}$, respectively, which are in good agreement with those observed on plant (ca. 0.1 and 1-2 $\mathrm{mm}$, respectively).

(iii) The formation of a wave at the metal/slag pool interface.

(iv) The formation of regular indentations in the shell surface (similar to oscillation marks).

(v) A meniscus shape similar to that observed in practice (no predefined shape is assumed in the model).

Qualitatively, the model appears to reproduce many of the natural phenomena occurring in the mould, e.g. slag film formation and meniscus shape. Furthermore, the model predictions for the heat flux, shell thickness and powder consumption (shown in Figures 3 and 4) indicate that the predictions are in very good quantitative agreement with plant data [7-11].

The model predictions have been used to gain insights into various mechanisms occurring in the mould; these are described below.

\subsection{Metal Flow Effects and Slag Entrapment}

The metal flowing out of the SEN creates a "double-roll" flow in the mould and a "standing" wave is formed at the

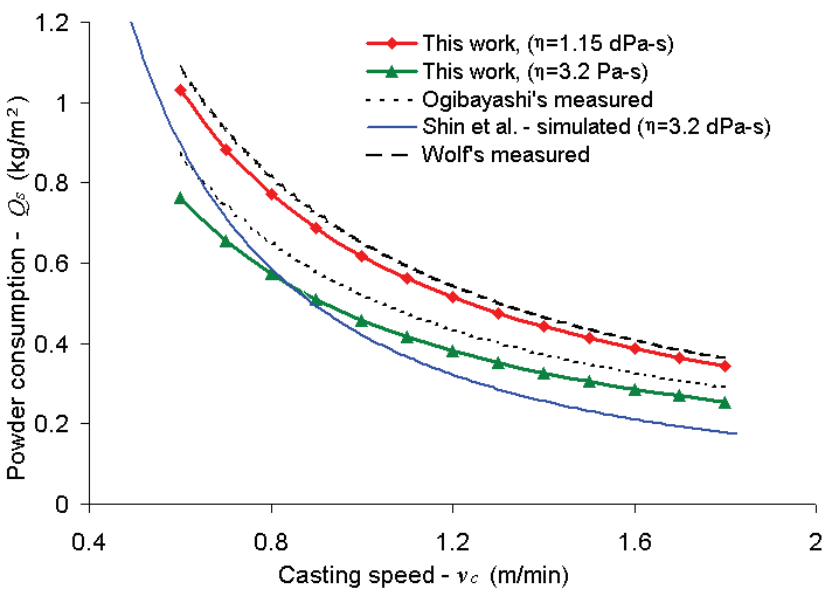

Figure 4. Powder consumption $\left(Q_{s}\right)$ as a function of casting speed [9-11].

metal/pool interface (Figures 1 and 5 (a)). The model was run in $3 \mathrm{D}$ (using coarser grid spacing) and it correctly predicts the formation of the surface waves. Furthermore, the model predicts that turbulent metal flow can lead to the formation of vortices which may cause slag entrainment (Figure $5(\mathrm{~b})$ ). These predictions are not new since both the standing wave and vortices have been reported previously from water-modelling and mathematical modelling work [12]. However, these results do provide further evidence of the model's ability to reproduce the natural phenomena occurring in the mould.

Slag entrapment occurs at higher casting speeds as a result of more turbulent metal flow. Entrapment occurs by (i) vortex formation or (ii) a process of "necking and detachment" resulting from differences in the flow velocities of the metal and slag [12]. Figure 6 shows the "necking and detachment" of the slag predicted by the model and clearly 


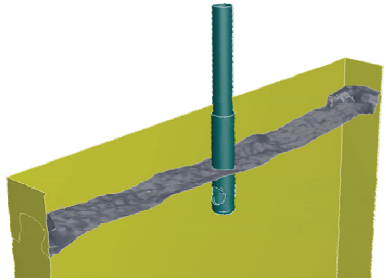

(a)

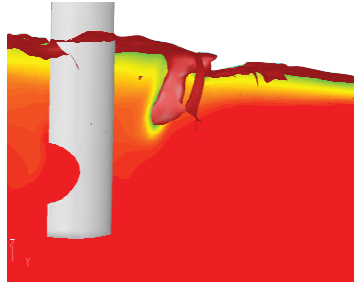

(b)
Figure 5. Metal flow results showing formation of (a) standing wave and (b) vortex and slag entrapment.

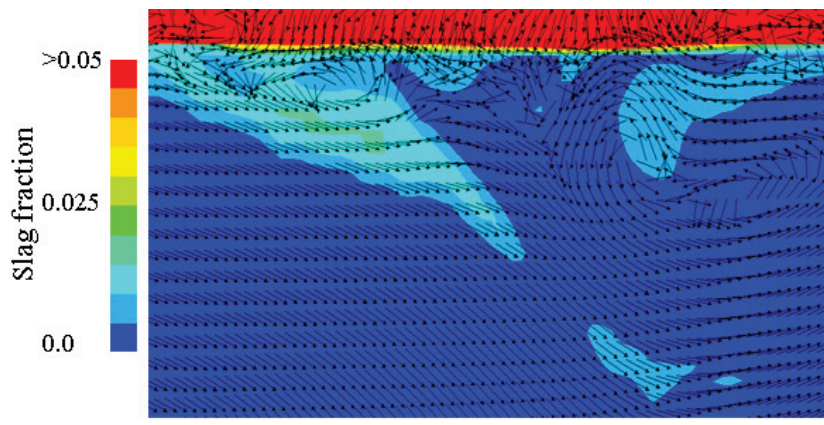

Figure 6. Modeling results showing "necking and detachment" of slag (light) into the metal bulk (dark) [13].

demonstrates that the model is capable of predicting natural (flow-related) phenomena occurring in the mould [13].

\subsection{The Effect of Oscillation Characteristics on Slag Infil- tration}

It was mentioned above that the thickness of the liquid slag layer $\left(d_{\text {liquid }}\right)$ determines the level of lubrication supplied to the shell. The powder consumption $Q_{\mathrm{s}}\left(\mathrm{in} \mathrm{kg} \mathrm{m}^{-2}\right)$ is frequently used as a lubrication index which is not surprising since $Q_{\mathrm{s}}=d_{\text {liquid }} \cdot \rho_{\text {liquid }} \approx 2550 d_{\text {liquid }}$, where $\rho_{\text {liquid }}=$ density of liquid slag. Powder consumption can be expressed in various forms, e.g. $Q_{\mathrm{t}}\left(\mathrm{kg}\right.$ tonne steel $\left.^{-1}\right)=Q_{\mathrm{s}} \cdot R / 7.6$ and the melting rate or mass flow rate $\left(\mathrm{MR}\left(\mathrm{kg} \cdot \mathrm{s}^{-1}\right)=\right.$ $2(w+t) Q_{\mathrm{s}} \cdot V_{\mathrm{c}}$ and where $R=2(w+t) / w \cdot t$ and $w$ and $t$ are the width and thickness of the mould.

Although there is general agreement that powder consumption $Q_{\text {s }}$ increases as the casting speed decreases and as viscosity $(\eta)$ decreases, there is no agreement on the effect of the oscillation characteristics on $Q_{\text {s }}$. It can be seen from Figure 4 that the model predicts that $Q_{\mathrm{s}}$ decreases as casting speed increases and viscosity was also found to exhibit an inverse relationship with $Q_{\mathrm{s}}$.

It is customary to express the oscillation in terms of the negative and positive strip times ( $t_{\mathrm{n}}$ and $t_{\mathrm{p}}$, respectively); $t_{\mathrm{n}}$ is the time in which mould velocity $\left(V_{\mathrm{m}}\right)$ is descending faster than the casting speed (i.e. $V_{\mathrm{m}}>V_{\mathrm{c}}$ see Figure 7 (a)) and $t_{\mathrm{p}}$ is remaining time in the cycle $\left(t_{\mathrm{n}}+t_{\mathrm{p}}=t_{\text {cycle }}\right)$. Negative strip time $\left(t_{\mathrm{n}}\right)$ is determined by the frequency $(f)$ and stroke $(s)$ and casting speed $\left(V_{\mathrm{c}}\right)$. The model was used to examine the powder consumption at various times in the oscillation cycle (Figure 7). The mould and the slag rim are at their highest positions in late $t_{\mathrm{p}}\left(t_{\mathrm{p}}^{\text {late }}\right)$ and their lowest position (i.e. closest to the shell tip) in early $t_{\mathrm{p}}\left(t_{\mathrm{p}}^{\text {early }}\right)$. Thus the mould is descending for all of $t_{\mathrm{n}}$ and ascending for most of $t_{p}$.

It can be seen from Figure 7 (b) that:

(i) The liquid film thickness $\left(d_{\text {liquid }}\right)$ increases during negative strip time $\left(t_{n}\right)$ (when slag rim is descending) and decreases during positive strip time (when rim is ascending).

(ii) The changes in solid slag film thickness $\left(d_{\text {solid }}\right)$ mirror those in $d_{\text {liquid }}$ (i.e. $d_{\text {solid }}$ increases when $d_{\text {liquid }}$ decreases and vice versa).

Kajitani et al. [14] have reported the results of an elegant, cold modelling experiment in which the thickness of an oil layer $\left(d_{\text {oil }}\right)$ was monitored through an oscillation cycle. It can be seen from Figure 7 (b) that $d_{\text {oil }}$ had a very similar transient to that of $d_{\text {solid }}$ and not that of $d_{\text {liquid }}$, which had been expected. We believe that this is due to the absence of (i) a slag rim and (ii) any heat flux in Kajitani's experiment [14].

Powder consumption $\left(Q_{\mathrm{s}}\right)$ is directly linked to $d_{\text {liquid }}$ ( $\left.Q_{\mathrm{s}}=d_{\text {liquid }}, \rho_{l} \approx 2550 d_{\text {liquid }}\right)$ so the model predicts that powder consumption increases when the mould and rim are descending (in $t_{\mathrm{n}}$ ) and decreases when the mould is ascending (in late $t_{\mathrm{p}}$ ). In fact, we will see later (Figure 10) that significant slag infiltration occurs in early $t_{\mathrm{p}}$ since $d_{\text {liquid }}$ is wide and the pressure in the gap is low which sucks liquid slag into the channel. The flow of molten slag into the channel (denoted by the dotted circle in Figure 8) for different times in the oscillation cycle showed that:

(i) A counter-current formed at site 1 midway through $t_{\mathrm{p}}$ $\left(t_{\mathrm{p}}^{\mathrm{mid}}\right)$ thereby restricting infiltration along with a horizontal slag flow in the direction of shell to mould.

(ii) The counter-current moved downwards and decreased as $t_{\mathrm{p}}$ progressed; this allowed some infiltration; slag flow was still in direction of shell to mould.

(iii) There was significant infiltration at 3 due to a change in flow direction (radially-outward to downward) in $t_{\mathrm{n}}$ when the mould is descending

(iv) At no period was there any negative consumption (i.e. upward flow).

\subsection{The Effect of Oscillation Characteristics on Heat Flux}

The horizontal heat flux is important because excessive heat flux can lead to longitudinal- and longitudinal cornercracking. The heat fluxes predicted by the model are in excellent agreement with those measured on plant $[7,8]$ as 


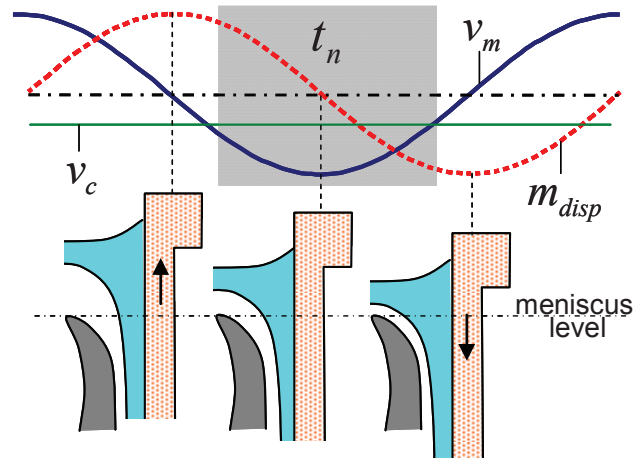

(a)

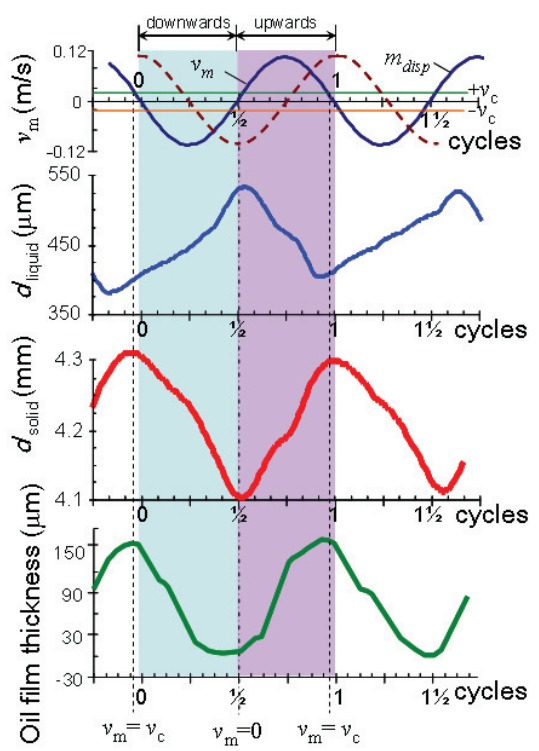

(b)

Figure 7. (a) Schematic drawing showing effect of mould oscillation; line = mould velocity $\left(V_{m}\right)$ dotted line $=$ mould displacement and (b) thicknesses of liquid $\left(d_{\text {liquid }}\right)$ solid $\left(d_{\text {solid }}\right)$ slag films and oil layer $\left(d_{\text {oil }}\right)$ (Kajitani et al. [14]).

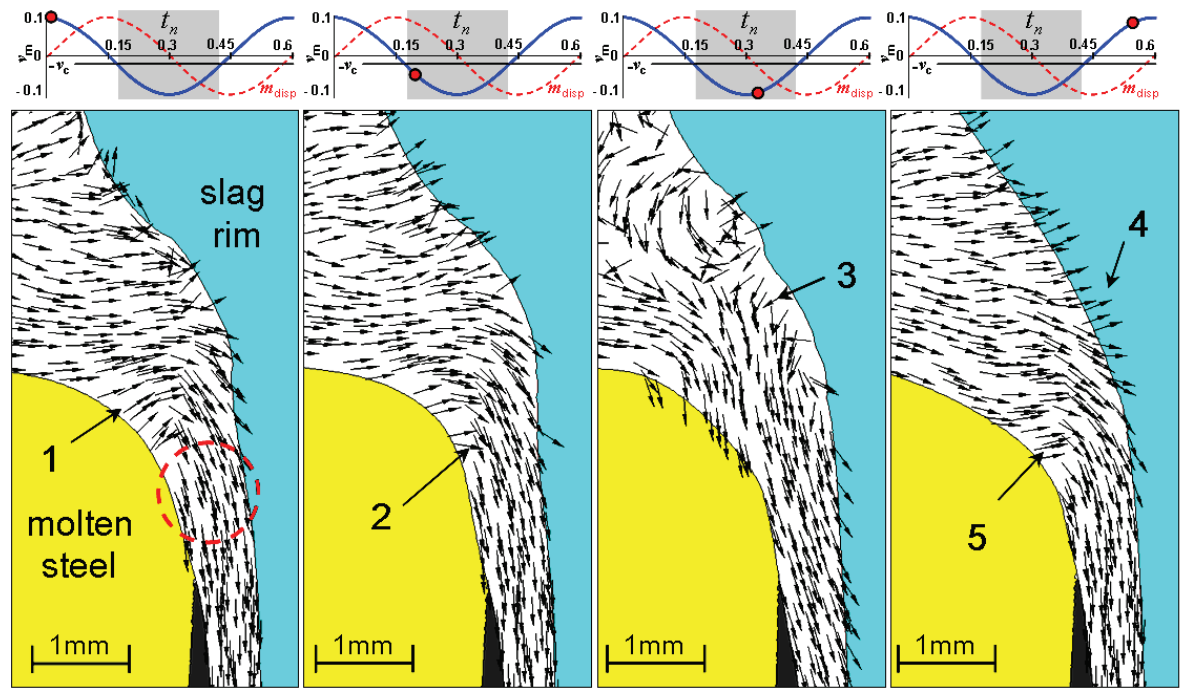

Figure 8. Predicted slag flow in the meniscus for $\mathrm{V}_{\mathrm{c}}=0.6 \mathrm{~m} / \mathrm{min}$ at four points (solid dot on mould velocity curve) during an oscillation cycle, a) at $t_{\mathrm{p}}^{\text {mid }}$ halfway through positive strip, b) $t_{\mathrm{n}}^{\text {start }}$ start of negative strip, (c) $t_{\mathrm{n}}^{\text {mid }}$ approximately half way through negative strip and (d) returning to $t_{\mathrm{p}}^{\text {mid }}$ halfway through positive strip.

shown in Figure 3. The heat fluxes predicted by the model were found to increase as the solid slag film decreased, $d_{\text {solid }}$, and the interfacial thermal resistance $\left(R_{\text {int }}\right.$, which is due to crystallisation of the solid slag film) decreased.

The mould reaches its highest position in $t_{\mathrm{p}}^{\text {late }}$ and when it starts to descend (in $t_{\mathrm{n}}$ ) it causes a change in the direction of the slag flow from radially-outward to downward (Figure 8 (b) to $8(\mathrm{c})$ ). This downward, slag flow brings cold, liquid slag from the upper regions of the slag pool; this cold, convective flow is responsible for the increasing heat flux during $t_{\mathrm{n}}$. The heat flux continues to increase as the mould descends (bringing the slag flow ever- closer to the shell tip) and causing shell solidification. Once the mould has reached its lowest point (in $t_{\mathrm{p}}^{\text {early }}$ ) another "tidechange" in the slag flow occurs and the cold, downward flow is replaced by a warm, radially-outward flow and there is a decrease in both heat flux and shell solidification in $t_{\mathrm{p}}$.

The variation of heat flux at various times in the oscillation cycle was determined using the model and the results are shown in Figure 9. 


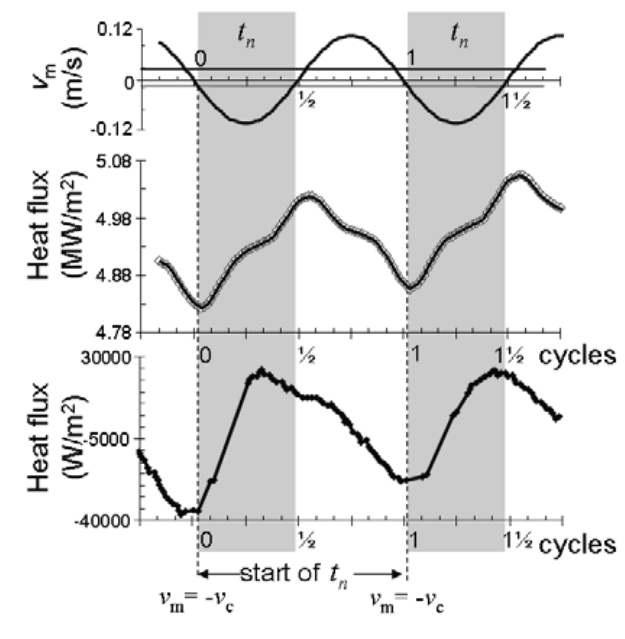

(a)

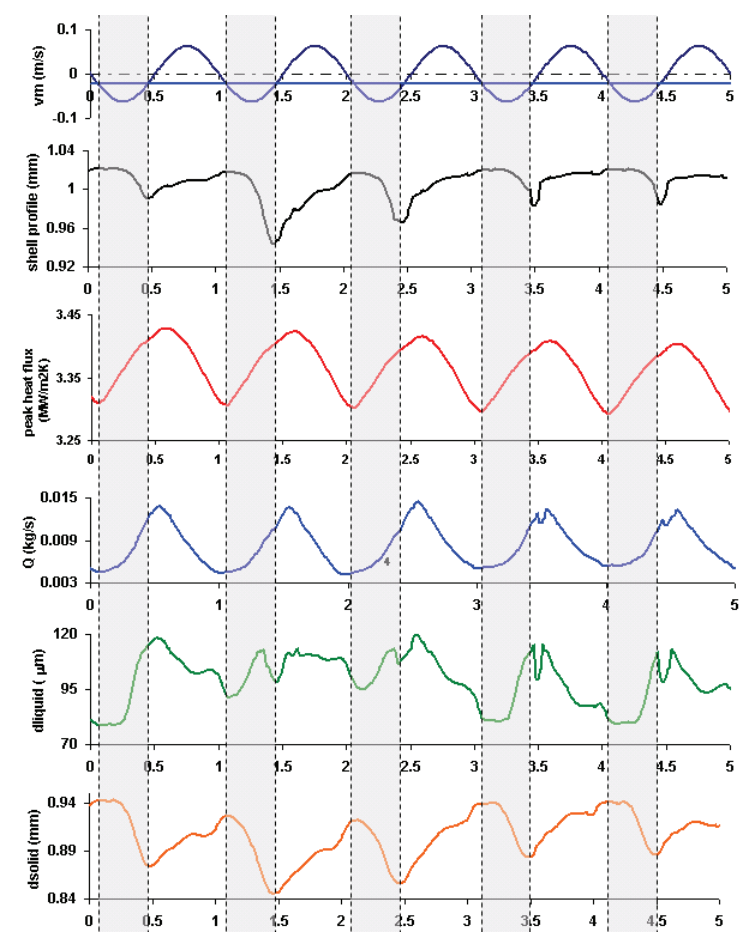

(b)

Figure 9. Changes during oscillation cycle (a) (from top) (i) mould velocity $\left(V_{\mathrm{m}}\right)$, (ii) heat flux (model) and (iii) measurements due to Badri et al. [15] and (b) (i) mould velocity, (ii) shell profile, (iii) heat flux (iv) powder consumption $\mathrm{kgs}^{-1}$, (v) thickness of liquid slag film, (vi) thickness of solid slag film; vertical lines denote $t_{\mathrm{n}}$ and $t_{\mathrm{p}}$.

It can be seen that:

(i) The heat flux increases significantly during negative strip time $\left(t_{\mathrm{n}}\right)$ when the mould/rim are descending; this is attributed to convective cooling created by cooler slag flowing downwards.

(ii) The heat flux decreases during positive strip time $\left(t_{\mathrm{p}}\right)$ when the mould is ascending.

(iii) The measurements due to Badri et al. [15] obtained using a bench-top continuous caster show exactly the same trends as those noted here in (i) and (ii).

It has also been shown here that the horizontal heat flux $(q)$ is an inverse function of the thickness of the solid slag film $\left(d_{\text {solid }}\right)$ and we have seen in Figure 7 (b) that $d_{\text {solid }}$ decreases during $t_{\mathrm{n}}$ and increases during $t_{\mathrm{p}}$. Thus there are similarities in the oscillation dependence of the powder consumption and the heat flux with increasing values through $t_{\mathrm{n}}$ into early $t_{\mathrm{p}}$.

\subsection{Inter-relationship of Shell Formation, Slag Infiltration and Heat Flux}

It was seen in Figure 9 (b) that both the liquid slag thickness and heat flux increased at the start of negative strip. Inspection of the initial shell formed at the meniscus shows that it is not uniform but has thick and thin regions corresponding to high $\left(t_{\mathrm{n}}^{\text {mid }}\right.$ to $\left.t_{\mathrm{p}}^{\text {mid }}\right)$ and low ( $t_{\mathrm{p}}^{\text {mid }}$ to $\left.t_{\mathrm{n}}^{\text {mid }}\right)$ heat flux periods, respectively (corresponding to cold-downward and warmoutward slag flows, respectively). The transient behaviour of various parameters through an oscillation cycle is shown in Figure 9 (b):

(i) At start of $t_{\mathrm{n}}$ the heat flux $(q)$ powder consumption $(Q)$ in the channel and $d_{\text {liquid }}$ are all at low values and $d_{\text {solid }}$ is near its maximum thickness and there is little shell growth at this time; the slag flow is horizontal (shell to mould) but changes to downwards as $t_{\mathrm{n}}$ progresses, and both the mould and rim descend.

(ii) At $t_{\mathrm{n}}^{\mathrm{mid}}, d_{\text {liquid }}$ is still thin, heat flux and powder consumption are relatively low and $d_{\text {solid }}$ is still thick and shell growth is slow; however, the slag flow is now downward

(iii) At the end of $t_{\mathrm{n}}, d_{\text {liquid }}$, heat flux and powder consumption all are at high values but $d_{\text {solid }}$ is close to its minimum value and shell growth is high because of the thin $d_{\text {solid }}$ and consequent high heat flux; slag flow is downward but about to change to a horizontal direction.

(iv) By $t_{\mathrm{p}}^{\text {early }}$ the $d_{\text {liquid }}$, heat flux and powder consumption are all near their maximum values and $d_{\text {solid }}$ is near its minimum value (the powder consumption is high because $d_{\text {liquid }}$ is wide and there is still sufficient downward flow) and shell 
growth is high; slag flow is still downward but gradually changing to horizontal.

(v) At $t_{\mathrm{p}}^{\text {mid }}$ the heat flux, powder consumption, $d_{\text {liquid }}$ and $d_{\text {solid }}$ all have median values and shell growth is slowing down; the slag flow is horizontal.

The heat flux $(q)$ variation through a cycle is about $4 \%$ which is of a similar magnitude to the variations in $d_{\text {solid }}$ (Figure $9(b)$ ). Thus heat flux is principally determined by an inverse relation with the solid slag thickness $\left(d_{\text {solid }}\right)$ but is also affected, to a lesser extent, by the direction of slag flow.

Through an oscillation cycle powder consumption $(Q)$ varies by a factor of 3 and $d_{\text {liquid }}$ varies by a factor of 2 . Thus $Q$ is principally determined by the liquid slag film thickness $\left(d_{\text {liquid }}\right)$ but the latter is related to the heat flux since it grows at the expense of $d_{\text {solid }}$ during periods of high heat flux. The direction of slag flow and flow velocity are also important to powder consumption.

\subsection{Mechanism for Oscillation Mark Formation}

Oscillation marks (OM's) are regular indentations formed along the surface of the steel. Defects (e.g. transverse cracks) are associated with deep OM's.

The model predicts the formation of regular indentations along the shell (Figure 2). The measured pitches of these depressions were found to be identical to the theoretical values for OM's, thereby indicating that they are the initial form of the OM's. However, the depth of these depressions was only $10-30 \%$ of that recorded for oscillation marks in typical plant conditions. Presumably, the depth of the OM increases as a result of further solidification and stresses arising from shell shrinkage.

The mechanism responsible for the formation of OM's was studied using the predictions of the model. Two published mechanisms [16-19] have hitherto attracted wide acceptance:

(i) The overflow mechanism in which the shell tip is overflowed by molten steel and the resulting meniscus solidifies leaving the shell with the characteristic oscillation mark shape.

(ii) The folded mechanism proposes that the shell tip is bent back in response to the pressure exerted by the slag rim.

An analysis of the predictions of the model developed in this study indicated an alternative mechanism was responsible for OM formation [20]. It was noted above that once the mould had reached its highest position that there was a tide change in the direction of the slag flow; the warm, outward flow was replaced by a cold, downward slag flow. It is proposed that as the slag rim approaches, the shell tip during the later stages of $t_{\mathrm{n}}$, the downward flow causes: (i) a depression (or dimple) in the liquid metal meniscus next to the shell tip and

(ii) rapid solidification of the molten metal next to the shell tip (including the dimple).

A key factor is the separation distance between slag rim and the liquid metal (next to the shell tip); a decrease in this separation distance will result in a deeper depression (deeper OM) and more intense solidification. Thus an increase in stroke length (s) will reduce the separation distance and hence increase $d_{\mathrm{OM}}$ (i.e. $d_{\mathrm{OM}} \uparrow$ as $s \uparrow$ ). The model predictions also showed that the depth of the oscillation mark increased as $t_{\mathrm{n}}$ increased $\left(d_{\mathrm{OM}} \uparrow\right.$ as $\left.t_{\mathrm{n}} \uparrow\right)$. The negative strip time is calculated via:

$$
t_{\mathrm{n}}=(60 / \pi f) \operatorname{arcos}\left(V_{\mathrm{c}} / \pi s f\right),
$$

where $f$ is the frequency $(\mathrm{cpm})$ and $V_{\mathrm{c}}$ is the casting speed $\left(\mathrm{m} \min ^{-1}\right)$. It can be seen that there are two terms in Eqn. (1), the first term is the dominant factor and the arcos term tends reduce the effect of the first term.

It was found that the effect of $V_{\mathrm{c}}$ on $d_{\mathrm{OM}}$ could be explained in terms of the effect of $V_{\mathrm{c}}$ on $t_{\mathrm{n}}$ i.e. an increase in $V_{\mathrm{c}}$ causes a decrease in $t_{\mathrm{n}}$ and hence a decrease in $d_{\mathrm{OM}}$ $\left(V_{\mathrm{c}} \uparrow t_{\mathrm{n}} \downarrow d_{\mathrm{OM}} \downarrow\right)$ ) and increase in stroke (whilst keeping $V_{\mathrm{c}}$ and $f$ constant) would increase both $t_{\mathrm{n}}$ and $d_{\mathrm{OM}}\left(s \uparrow t_{\mathrm{n}} \uparrow\right.$ $\left.d_{\mathrm{OM}} \uparrow\right)$. The frequency appears in both terms of Eqn. 1 but the first term is dominant and $t_{\mathrm{n}} \uparrow$ as $f \downarrow$ and so increased frequency leads to a decrease in $d_{\mathrm{OM}}\left(d_{\mathrm{OM}} \downarrow\right.$ as $\left.f \uparrow\right)$. All of these predictions are consistent with plant observations.

It can be seen from Figure 8 that when a tide change occurs there follows a period of confused flow in the mouth of the shell/mould channel and a certain time is needed to establish a stable flow. These periods of confused flow reduce the time available for slag infiltration. Furthermore, as the frequency is increased these periods of confused flow will become relatively more important and cause a reduction in time available for slag infiltration. This behaviour could account for why (i) increased frequency reduces $d_{\mathrm{OM}}$ and (ii) why Navier-Stokes calculations always show $Q_{\mathrm{s}}$ increasing with increasing $f\left(Q_{\mathrm{s}} \uparrow\right.$ as $\left.f \uparrow\right)$ whereas plant observations indicate the reverse relation $\left(Q_{\mathrm{s}} \downarrow\right.$ as $\left.f \uparrow\right)$.

\subsection{Fluctuations with Time}

When the mould is viewed from close quarters it does not exhibit any sign of turbulence since it appears peaceful and steady. In fact it is in a constant state of fluctuation. These fluctuations start in the SEN where "bounce-back" of metal flow causes a counter-current flow in the lower region of the SEN which interferes with flow from the port and causes some pulsing of the metal flow.

Consequently, the wave, (shown in Figures 2 (a) and $5(a))$ is in a constant state of fluctuation and vortices 


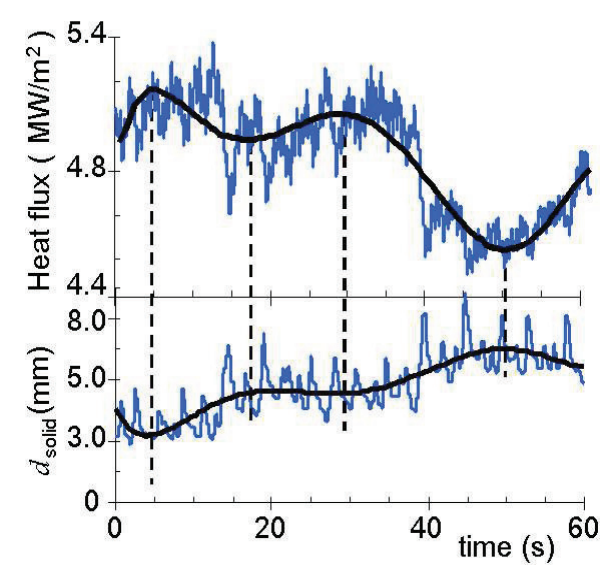

Figure 10. Heat flux and solid slag film thickness $\left(d_{\text {solid }}\right)$ as functions of time (100 cycles) $V_{\mathrm{c}}=0.6 \mathrm{~m} \mathrm{~min}^{-1}$.

(such as that in Figure 3 (b)) can disappear and reform on either side of the SEN.

The heat flux recorded at the reference point (sited $45 \mathrm{~mm}$ below meniscus) and solid slag thickness $\left(d_{\text {solid }}\right)$ were monitored over 100 cycles (Figure 10). It can be seen that there are:

(i) high frequency fluctuations (cycle times $0.6 \mathrm{~s}$ ) associated with mould oscillation.

(ii) low frequency fluctuations with cycle times of about $20 \mathrm{~s}$.

There are continual (and cyclic) changes in heat flux over time and these are mirrored by inverse changes in the thickness of solid slag film. These fluctuations are thought to be responsible for the observed variations in the depth of oscillation marks.

\section{Conclusions}

1. The model developed in this study correctly predicts many of the natural phenomena occurring in the mould (e.g. formation of solid and liquid slag films, slag pools, standing waves, slag entrapment, meniscus shape and oscillation marks).

2. The predicted values for powder consumption, heat flux, shell and slag film thickness are in good agreement with plant data.

3. The powder consumption increases steadily through negative strip time $\left(t_{\mathrm{n}}\right.$, when rim + mould are descending) reaches a maximum during $t_{\mathrm{p}}^{\text {early }}$ and decreases steadily through later stages of positive strip time $\left(t_{\mathrm{p}}\right.$, when rim + mould ascending); the highest infiltration occurs in late $t_{\mathrm{n}}$ and early $t_{\mathrm{p}}$ when the liquid film is wide and slag velocities are high.
4. The heat flux increases gradually during $t_{\mathrm{n}}$ and decreases during $t_{\mathrm{p}}$; the heat flux is an inverse function of solid slag film thickness and may also be affected by slag velocity.

5. The powder consumption, heat flux and shell solidification are inter-related through the thicknesses of solid and liquid slag films, which, in turn, have an inverse relationship.

6. A new mechanism is proposed for the formation of oscillation marks; when the mould is descending it induces a cold, downward flow in the slag pool which (a) causes the formation of a depression (or dimple) in the liquid metal surface next to the shell tip and (b) rapid solidification of the metal (including the dimple). The predicted dependencies of oscillation mark depth on. casting speed, stroke and frequency are consistent with plant observations.

7. Time is required to establish a stable, slag flow following a tide change and it is suggested that increasing frequency will tend to reduce the time available for stable slag infiltration which could account for increasing frequency causing (a) a decrease in the depth of OMs ( $\mathrm{d}_{\mathrm{OM} \downarrow} \downarrow$ as $\mathrm{f} \uparrow$ ) and (b) the observed decrease in powder consumption $\left(\mathrm{Q}_{\mathrm{s}} \downarrow\right.$ as $\mathrm{f} \uparrow)$.

8. Metal flows and slag flows are in a constant state of fluctuation; both high frequency fluctuations (related to mould oscillation) and low frequency fluctuations were identified.

\section{References}

[1] K. C. Mills and A. B. Fox, ISIJ Intl. 43 (2003), 1479.

[2] P. E. Ramirez-Lopez, P. D. Lee and K. C. Mills, ISIJ Intl. 50 (2010), 429.

[3] J. I. Liow, M. Rudman and P. Liovic, ISIJ Intl. 41 (2001), 225.

[4] P. E. Ramirez-Lopez and R. D. Morales, Ironmaking Steelmaking 33 (2006), 157.

[5] J. U. Brackbill, D. B. Kothe and C. Zemach, J Comput. Phys. 100 (1992), 335.

[6] R. Ramirez-Lopez, PhD Thesis, Imperial College, London, Dept Materials (2010).

[7] M. Hanao and K. Kawamoto, ISIJ Intl. 48 (2008), 180.

[8] M. Suzuki, S. Miyahara, T. Kitagawa, S. Uchida and Kokimoto, Tetsu-to-Hagane 78 (1992), 113.

[9] M. Wolf, Proc. $2^{\text {nd }}$ Europ. Conf. on Continuous Casting, Dusseldorf, June 1994.

[10] S. Ogibayashi, Nippon Steel Technical Report 34 (1997), 1.

[11] H. J. Shin, S. H. Kim, B. G. Thomas, G. G. Lee, J. M. Park and J. Sengupta, ISIJ Intl. 46 (2006), 1635.

[12] S. Feldbauer and A. W. Cramb, $13^{\text {th }}$ PTD conference Proceedings 327 (1996).

[13] K. C. Mills, P. E. Ramirez-Lopez and P. D. Lee, Proc Sano Symposium, held Tokyo, Sept. (2008).

[14] T. Kajitani, K. Okazawa, W. Yamada and H. Yamamura, ISIJ Intl 46 (2006), 1432. 
[15] A. Badri, T. T. Natarajan, C. C. Snyder and A. W. Cramb, Metall. Mater. Trans. 36B (2005), 355 and 373.

[16] H. Tomono, Ph. D Dissertation, Ecole Polytechnique Federale de Lausanne, Lausanne, Switzerland (1979).

[17] P. Ackermann, Ph. D Dissertation: Ecole Polytechnique Federale de Lausanne, Lausanne, Switzerland (1983).
[18] E. Takeuchi and K. Brimacombe, Metall. Trans 15B (1984), 493.

[19] T. Emi, NOH-BOS Conf Proc. 61 (1978), 350.

[20] P. Ramirez-Lopez, K. C. Mills, P. D. Lee and B. Santillana, Metall. Mater. Trans. 43B (2012), 109. 